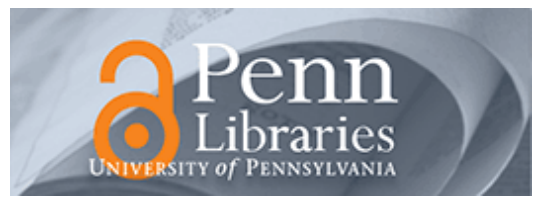

Studies in Visual Communication

Volume 6

Issue 1 Spring 1980

Article 6

1980

\title{
Studying the Home Mode: An Exploration of Family Photography and Visual Communication
}

Christopher Musello

\section{Recommended Citation}

Musello, C. (1980). Studying the Home Mode: An Exploration of Family Photography and Visual Communication. 6 (1), 23-42. Retrieved from https://repository.upenn.edu/svc/vol6/iss1/6

This paper is posted at ScholarlyCommons. https://repository.upenn.edu/svc/vol6/iss1/6

For more information, please contact repository@pobox.upenn.edu. 
Studying the Home Mode: An Exploration of Family Photography and Visual Communication 


\section{Studying the Home Mode: An Exploration of Family Photography and Visual Communication}

\section{Christopher Musello}

Family photographs fill the desk drawers, albums, walls, attic chests, and closeted boxes of our homes in ways that personal diaries, writings, or documents never have and perhaps never will. They are produced in this country at a prodigious rate-Wolfman (1974) estimated the output of amateur photographs in 1973 at over 6 billion-and picturetaking is widely considered an appropriate activity in a broad range of social events in the family. As a craft, it is transmitted largely on an informal basis through word of mouth and imitation. Its products are employed unself-consciously in an ongoing process to meet daily needs, interest, and obligations. Family photography is a pervasive and sustained form of symbolic behavior producing a vast resource of "native documentation." Folklorists, sociologist, psychologists, anthropologists, and others have not surprisingly been drawn to these materials both as statements about social life and personal experience and as data of culture (cf. Worth 1972). Studies attempting to articulate a system for decoding these materials have proliferated, and speculation about their functions and significance is quite extensive. Yet actual fieldwork examining the nature and usage of family photography and the conditions which support and produce it is limited. This paper reports on a research project designed to produce a general description of family photography as it is pursued in daily life and to examine its properties as a form of documentation and communication (Musello 1977).

I have sought here to systematically describe and characterize home mode photography ${ }^{1}$ as a rule-governed and socially patterned communicative process. This is an ethnographic approach to visual communication, which examines photography as social activity and photographs as the symbolic artifacts of that activity. From this perspective the researcher examines who uses the medium, in what contexts, for what purposes, and under what social and cultural rules, conventions, and restrictions (Worth 1976; Chalfen 1974). Patterns in photographic activity (photographs and picturetaking) are sought as well as the interrelation of these patterns with context and function (cf. Hymes 1974). The research finds its antecedents in Worth's ethnographic studies of visual codes (Worth and Adair 1972; Worth 1974) and in Hymes' ethnographies of communication $(1964 ; 1974)$ and subordinates the examination of film codes and cognitive/perceptual aspects of the mediation to the study of the social behavior and activities which produce these forms. Films and photographs are regarded as being shaped by so-

Christopher Musello is a Doctoral Candidate in Communications at the University of Pennsylvania. His research has focused on methods for the analysis of photographs and the study of material culture as communication. cial norms rather than psychological or technical variables (Chalfen 1974; 1975a).

For the descriptive purposes of this study, communication activities and their artifacts will be analyzed through a structure of events and components. These descriptive units have been adopted and expanded from Chalfen's (1974) sociovidistic framework to provide for a more thorough description of still photography activities. They include: (1) planning, (2a) behind-camera shooting, (2b) on-camera shooting, (3) processing, (4) editing, and (5) exhibition. These units are to be described in integral relation to a set of five communicational components: (1) participants, (2) settings, (3) topics, (4) message form, and (5) code. Each conceptual unit will be explained below. The events and components yield a grid of thirty relationships for systematic analysis (see Table 1) through which we can "delineate the structural qualities of both the symbolic forms per se and the social activity and relationships that surround the production and use of the visual forms"' (Chalfen 1976:42).

At the time of this study ${ }^{2}$ the methodology had been applied only to an examination of teen-age filmmaking and home moviemaking (Chalfen 1974; 1975a). In applying it in this study, my intention has been to provide an initial description of home mode still photography and an evaluation of its communicational functions, both for the particular data it might yield about the mode and as a necessary base from which to assess its value as a data source.

A sample of twelve families was used for the study; eight of the families completed a full interview schedule averaging five to six hours, while members of four families were interviewed for less time. The sample size is too small to establish trends or patterns; accordingly, informants were chosen fortuitously. The families were all Euro-American, predominantly middle class; all had children, and marriages ranged from three to thirty years' duration. Two sources of data were relied upon: interviews and observation. The interviews involved two phases: (1) directed interviews with the families aimed at characterizing the events and components of their photographic processes and (2) discussion and analysis of both those images which the families had produced and those made by others but included in their collections. Family members were asked to describe, discuss, and evaluate a sample of photographs from each storage and display unit, and to explore the distinctions between these units, their criteria for evaluating their images, and their functions and formal/syntactic intentions in shooting particular photographs. Observation focused on family interactions in viewing pictures (in all cases the parents were observed in the activity, while in five cases these occasions evolved into full family events), and on the relation of informants' statements about their photographs, to what the researcher saw in the 
Table 1

The Sociovidistic Framework

\begin{tabular}{|c|c|c|c|c|c|}
\hline & Participants & Settings & Topics & Message Form & Code \\
\hline \multicolumn{6}{|l|}{ Planning } \\
\hline \multicolumn{6}{|c|}{$\begin{array}{l}\text { Shooting: } \\
\text { on-camera }\end{array}$} \\
\hline $\begin{array}{l}\text { behind- } \\
\text { camera }\end{array}$ & & & & & \\
\hline
\end{tabular}

Processing

Editing

Exhibiting

pictures. This resulted in a survey of photograph collections, with an analysis of who shoots, who the participants are, what the settings are, and what the topics and code features are.

\section{The Events of the Home Mode}

The approach in this study has been to take a detailed look at the ways in which individual families integrate the photographic medium into family life and experience. The method is qualitative rathier than quantitative, and no pretence to sample validity or quantitative measures is implied. Nonetheless, in the following pages generalizations regarding the nature of the mode will be drawn from patterns and consistencies observed in the practices of the families studied. As such, the value of these findings will lie less in general verifiability (although it is felt that many of the findings here will be borne out by further systematic research) than in implications regarding how the mode is employed and in its properties as a communicative form. The analysis will begin with a discussion of the events of the home mode.

The home mode events include the full range of behaviors, activities, or performances surrounding the production, organization, and use of family photographs. Through the description of these events we locate the photographs within the flow of interpersonal interactions and the social contexts from which they take their form and significance.

\section{Planning Events}

These events incorporate any activity or performances in which decisions are made about when to take pictures, of what to take pictures, and how to take them. We are dealing here not only with choices and decisions made in direct anticipation of, or in response to, a "picturemaking" event, but also with any decisions made prior to the event which would affect when people are likely and able to take pictures. Factors here would include when film is kept on hand, the number and accessibility of cameras, when they are "brought along," and choice of film.

A family's "preparedness" to shoot may be considered a form of planning, be it conscious or not. In these terms, most families in this study claimed to have film and cameras readily available and to use film slowly and keep rolls in cameras for extended periods. Choice of camera may also become a factor, particularly as the small automatic-type cameras now popular have not only induced many to shoot who would not have before but have also permitted many to shoot where and when they formerly could not, on hiking trips, for example. Most of the families do not own flash equipment and resist its perceived difficulties; as a result many families' picturetaking was restricted primarily to outdoor settings. Planning in this mode was never found to be extensive; rather, choices and decisions were made piecemeal, often without relation to one another.

As to planning in the more formal sense, people generally carry a camera only when they have a purpose; few subjects in this sample carried cameras simply to be prepared for pictures, except perhaps on vacations. This planning, however, is of a general nature, never more than a broad notion of occasions and subject matters to be documented. Planning exists to the extent that people are predisposed to shoot certain things at certain times by their sense of the purposes and appropriate uses of photography. Thus, each fam- 
ily stated at minimum that they planned to shoot and carried the camera on "special occasions" and "whenever the family was going somewhere," usually listing a repertoire of typical and perhaps necessary events destined for the family document. The list uniformly included such events as Christmas, birthdays, Easter, vacations, and family gatherings.

Planning thus might extend to occasions and general subject matters (most often people), but beyond a decision to shoot a great number of pictures to cover mistakes or to provide extras for distribution, any planning regarding specific shots or techniques to be used in shooting was rare among home moders. The consistent exception was "traditional" pictures. These included both specific repeated pictures and shots of traditional events planned for each year at regular intervals, often taken in a fixed setting in a consistent format. $^{3}$

Finally, a generalizea, discriminating sensibility might also develop over time to condition shooting. For as people view their photographs and become aware of preferences, interests, and problems in viewing, they occasionally develop prescriptive and proscriptive plans for future shooting of similar events. Adjustments of this kind include instances where people found their collections to be "repetitive and boring," and reduced shooting, or when they found the need for reference points in slide shows and so planned the inclusion of street and place signs.

Planning was limited as a conscious process and little time was spent on it. Several subjects stated that planning "never works," and most did not even feel that it was necessarily desirable. For beyond making provision for the coverage of a small structure of events and people, value was placed on "catching" the unanticipated, the spontaneous, and the candid. Planning, therefore, seems largely a matter of routine or patterned predispositions and habits in this mode that influence the ability to, and likelihood of, taking pictures as well as any decisions concerning what and when to shoot.

\section{Shooting Events}

The shooting event is divided into two elements, behind-camera and on-camera, in order to allow for a more precise characterization of the message form. However, it should be understood that these analytically distinguished activities constitute aspects of but one interactive process.

Behind-camera events. These events incorporate any activities or behaviors not on-camera which structure the use of the camera. They include camera techniques, the maker's "shooting aesthetic," and all efforts to direct subjects being photographed. They also include consideration of patterns and tendencies in shooting which develop and/or persist over time.
Most home moders feel they "just take pictures." As with the planning events, and with essentially all events of the home mode, primary attention lies not in the elements and processes of mediation, but rather in the subject matter. In most instances this orientation is based on an "understanding" of photography as a mechanical and "realistic" form of recording. As family photographers' understanding and use of the medium become more complex, they may actively incorporate technical/aesthetic considerations and at times even aspire to an "artful" depiction of their subjects. Indeed, the range of skills evidenced in the use of the camera by family photographers may be extremely broad, as can their critical vocabulary and their for$\mathrm{mal} /$ syntactic appreication of the medium. However, despite these skills or suggested competence, the family photographers in this sample generally set out simply to "record" what was before their cameras, thus applying a greatly simplified set of standards to their shooting while concerning themselves primarily with on-camera activities.

Formal manipulation or evaluation seems essentially irrelevant to home moders, although some minimal factors may be consciously attended to in the service of this "recording" process. "Centering" is the factor most frequently considered; "background," "getting all of the subject in," "getting detail" in faces, composition, and proper lighting follow. Although many of the family photographers mistrusted their ability to get what they wanted, all of them expressed a preference for simply shooting "a lot," particularly on important occasions.

Home moders' shooting might nonetheless be characterized by loosely defined "styles," to be seen in terms of the relationship between cameraman and subject; the distinct expectations for, and efforts invested in, each form of shooting; and the pattern of component considerations which influence each. The most prevalent style, in this sense, is the posed picture, even though the families uniformly expressed a preference for spontaneous, "natural" images. This method was generally prescribed by home moders for portraits, "serious and formal occasions," and "special events," but was most often resorted to for the control it afforded. Many home moders feel candid shooting is simply too difficult and are willing to sacrifice "naturalness" for control. As a result, when posing pictures, most photographers claim to feel a responsibility for "the total picture" including background, lighting, composition, and the arrangement or direction of subjects. Yet in most instances the pose is used simply to fix the subject without the subsequent effort at formal control.

The aim of the candid/spontaneous style, by contrast, is to minimize the photographer's intrusion through shooting discreetly in order to "catch" the "everyday," the "typical," and the "natural." Control 
of formal elements is not expected here, and many photographers in fact claimed that candid shooting essentially "exonerates" them of responsibility for any technical considerations. Luck, timing, and patience are generally felt to be the photographer's tools for these purposes, and while photographers at times directed subjects to ignore them, they generally relied on surprising subjects in one way or another.

The interactive/spontaneous style of shooting differs from the candid most dramatically in its intent and approach to the subject. The image resulting from this style will most often appear to be merely a candid shot. But, as opposed to the candid/spontaneous style, the photographer actively intrudes with his camera here as an element of, or even to stimulate, an interaction between cameraman and subject. Frequently in these events the photograph is of secondary importance to the interaction that motivated it. As with surprise candid shooting, this approach is directed primarily at close friends or family ("someone who won't get mad at me"'), and it tends to occur in group shooting situations or as people are "fooling around" or "sneaking up on" or "joking" with one another. This is perhaps the least-used shooting approach, but it is significant in the shooting of those families who photograph one another most informally, have the least rigid concept of the functions and "proper" uses of photography, and generally enjoy shooting. In this sense, further research may find this style of shooting predictive of a particular family orientation to photography.

These styles of shooting are not presented as original or precise formulations, but rather suggest common strategies employed by home moders when photographing friends and family. Their significance lies in the patterning they establish in the use of the camera with respect to the relations between subject and photographer; to the expectations they establish in photographer and viewer alike for control and "intentionality" on the maker's part; and to the conventionalized assumptions of the "appropriateness" of the different forms for different topics and participants. Home moders, for example, would not sneak up on the bride and groom at the altar to surprise them with a picture. The camera styles affected in behind-camera activities, then, are shaped and patterned by social convention, and they in turn play an important part in broadly shaping what and how home moders will photograph.

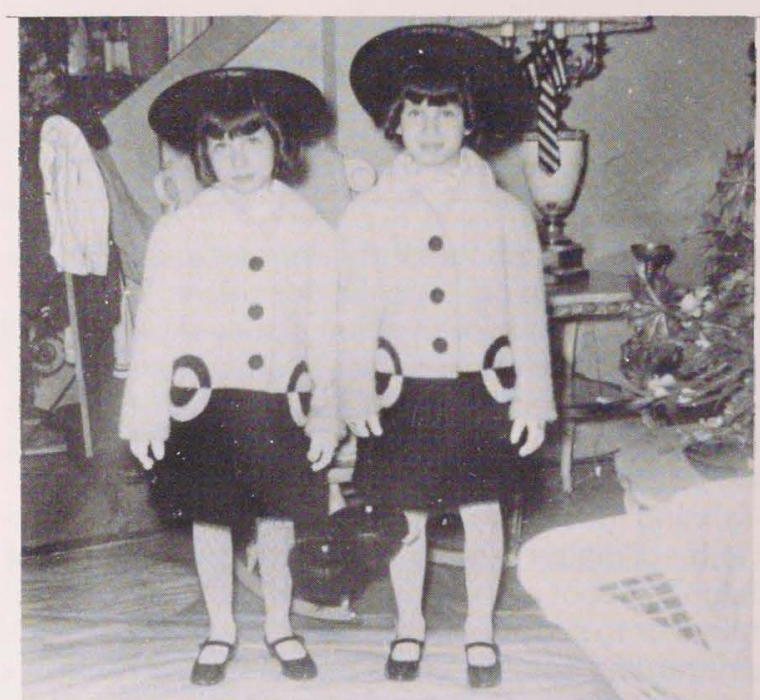

Figure 1 An Easter photograph. (Courtesy of Sam and Anna Fannelli)

Another patterning of the shooting event is more readily seen in the various "shooting routines" family photographers establish in the treatment of recurring subjects. Easter, for example, is frequently recorded in pictures of children with new outfits (Figure 1).

Christmas is recorded through a structure of secular events including snapshots of the tree and unopened presents and of the children opening the gifts and displaying them (Figure 2). Consistencies in these routines could be identified in the entire sample of families.

Shooting was also structured at times by explicit or implicit attempts to construct narratives documenting trips or special events and by a technique consistently employed by home moders that might be called "configurational shooting." This photographic routine was frequently employed at births, weddings, family gatherings, and other special occasions (Figures $3 \mathrm{a}$ and b). It involved posing participants in a number of combinations in order to depict a variety of associations, relationships, and bonds.

Finally, this research has suggested that the quantity, techniques, and subject matters of shooting vary interdependently over time. It was observed that when parents are young they produce the most photographs and that shooting will often be at its peak during the first years of the first-born's life and taper off after three to six years. Picturetaking may then decline completely or continue at a minimal level until a resurgence occurs as the children reach their late teens, and the family begins to travel and/or grandchildren arrive. In many cases shooting was at its most informal and spontaneous with younger photographers, who often shot "interactively" and covered a comparatively broad range of subjects. With marriage and the birth of the first child, shooting most often became increasingly family-oriented and focused overwhelmingly on the child. Photography of the first-born is perhaps the least structured, as parents shoot continually and 


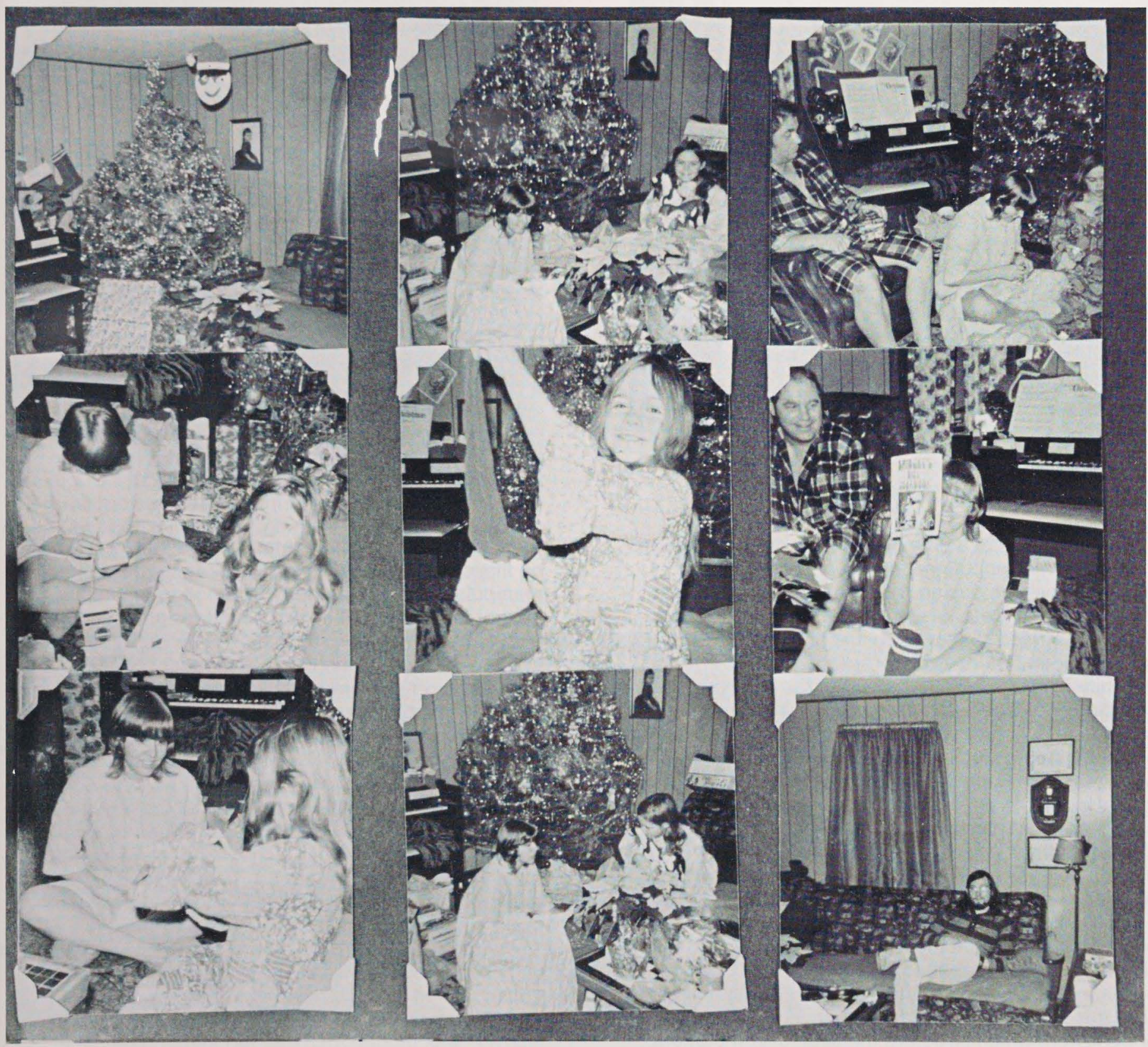

Figure 2 An album page of Christmas photographs. (Courtesy of John and Arlene Westphal) 

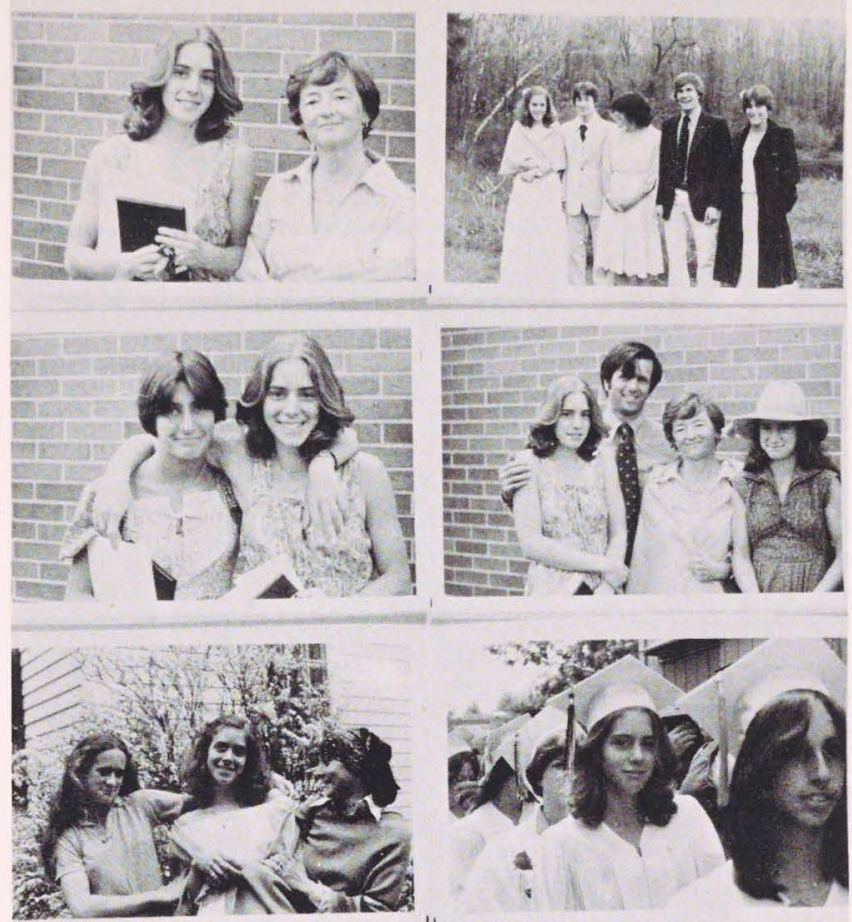

Figure 3 (a and b) "Configurational shooting." (Courtesy of Richard and Martha Perkins; Donald Gribbons)

spontaneously, but as the baby grows and successive children arrive, shooting may become perfunctory, relying heavily on posing. We can also note that with the oldest families in this study, shooting of the grandchildren seemed similar, both in intent and technique, to the shooting of the first-borns. ${ }^{4}$

While family photographers generally consider their shooting spontaneous and responsive to the subjects of the moment, their shooting seems to be patterned and more rule-governed than they believe it to be. And while these photographers attend only minimally to formal manipulation of the medium's code elements, conventional strategies for using the camera, and shared routines and notions regarding how one "'appropriately" takes pictures, serve to structure both what and how family photographers photograph.

On-camera events. As previously mentioned, all photographs in which the subject is aware that he or she is being photographed represent a collaboration between the subject and the image maker. In this analysis, the on-camera events focus on all those activities or behaviors which structure the subjects on-camera, including their own efforts to "present" themselves.

It is overwhelmingly the case with home mode photography that the ultimate evaluation of a photograph will lie in the image's success as a likeness. How the image's subjects are presented, how they look, what they are doing, and how "'funny," "'typical," or "'appropriate" their gestures and expressions may be are all significant as evaluative criteria. The behaviors of
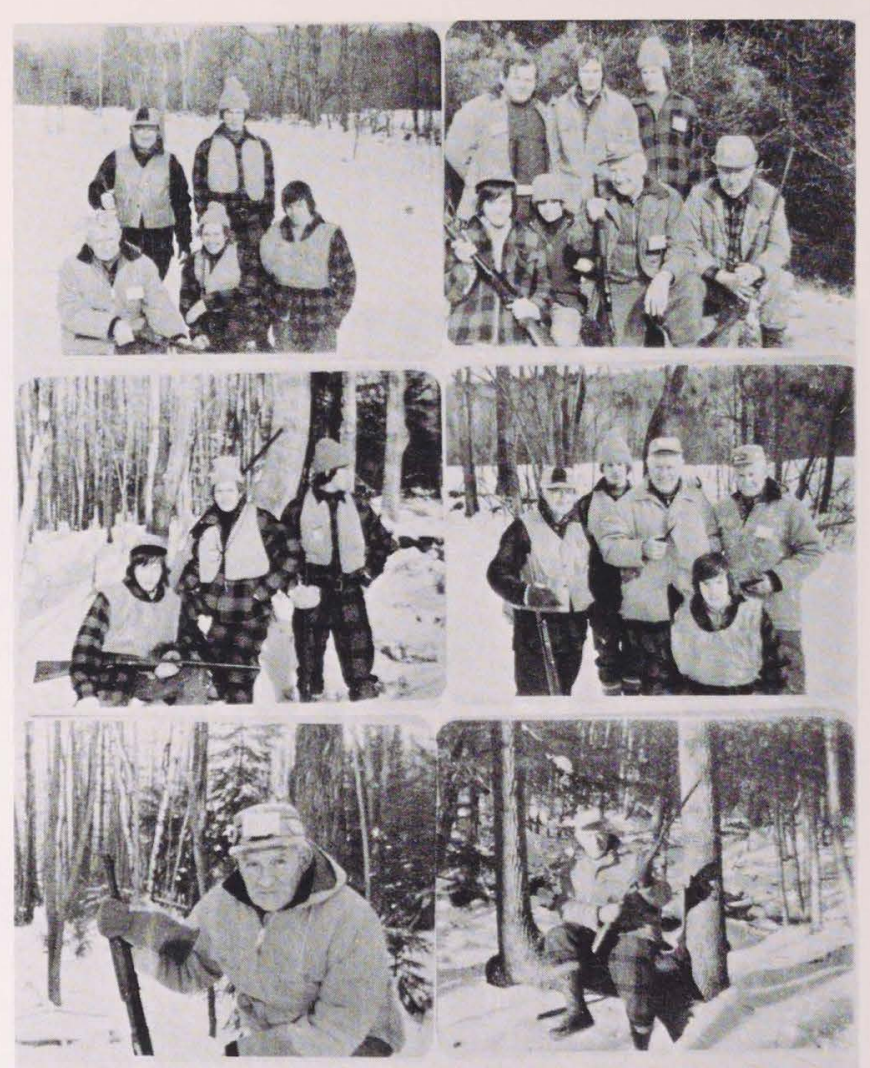

the subject and the moments at which they are fixed on film constitute, then, a major target of the symbolic manipulation in this mode. The shooting technique and environment of shooting will function significantly to shape these behaviors, but there is as well a complex of conventions, expectations, and behaviors attributable to the on-camera event which influence and shape the final product.

Most parents in the sample offered a paradigm for age- and sex-related behavioral expectations for children vis-à-vis the camera. Young children are considered easiest to shoot, submitting to almost anything until they are three or four years old, when they learn to pose themselves. During childhood years kids are thought to be impatient but still "appreciative of the attention," and boys are considered harder to pose and prevent from "'mugging" than girls. It is generally agreed that children beyond age twelve are the most difficult and uncooperative subjects. While this model was not subjected to any systematic examination in this study, it nonetheless assumes significance as a widely shared "folk model" of expected and conventional sex- and age-typed photographic behavior. It can also be pointed out that the pattern of rising difficulty associated with the aging of children seems consistent with the decline in spontaneous and continual shooting and the increasing reliance on posed pictures taken in a limited range of special events.

Adults generally express little enthusiasm for having their pictures taken, especially as they gain weight or feel that they are showing signs of age. By convention, most prefer to be photographed when "looking good" and when able to control their presentation. It is not unusual for husbands and wives to restrict their shooting of each other. 
The most salient and often commented-upon form of on-camera behavior is the pose. Many individuals frequently pose themselves without direction when a picture is to be taken, even if a candid shot is sought by the photographer. The positions struck have demonstrated a marked consistency across families and contexts in the sample of this study, and it seems plausible that a catalog of poses might successfully be developed. ${ }^{5}$ The origin and nature of these poses as photographic behavior, and their relation to such characteristics as sex and age, bear further analysis. In Figure 4, for example, the poses are highly stylized and possibly imitative of conventional "glamor" poses of the time. They seem clearly sexually stereotyped. Such poses as seen in Figure 5 are also "stylized" and were associated consistently through the sample with young males.

The studio pose represents an additional form of on-camera event. It is, however, largely an artifact of the photographer's direction and the specific conventions guiding this event. And, finally, in spontaneous pictures the subject is granted greater leeway in movement and behavior. "Mugging" is a frequent response and, generally speaking, each family has a member who consistently jokes and "makes faces" for the camera.

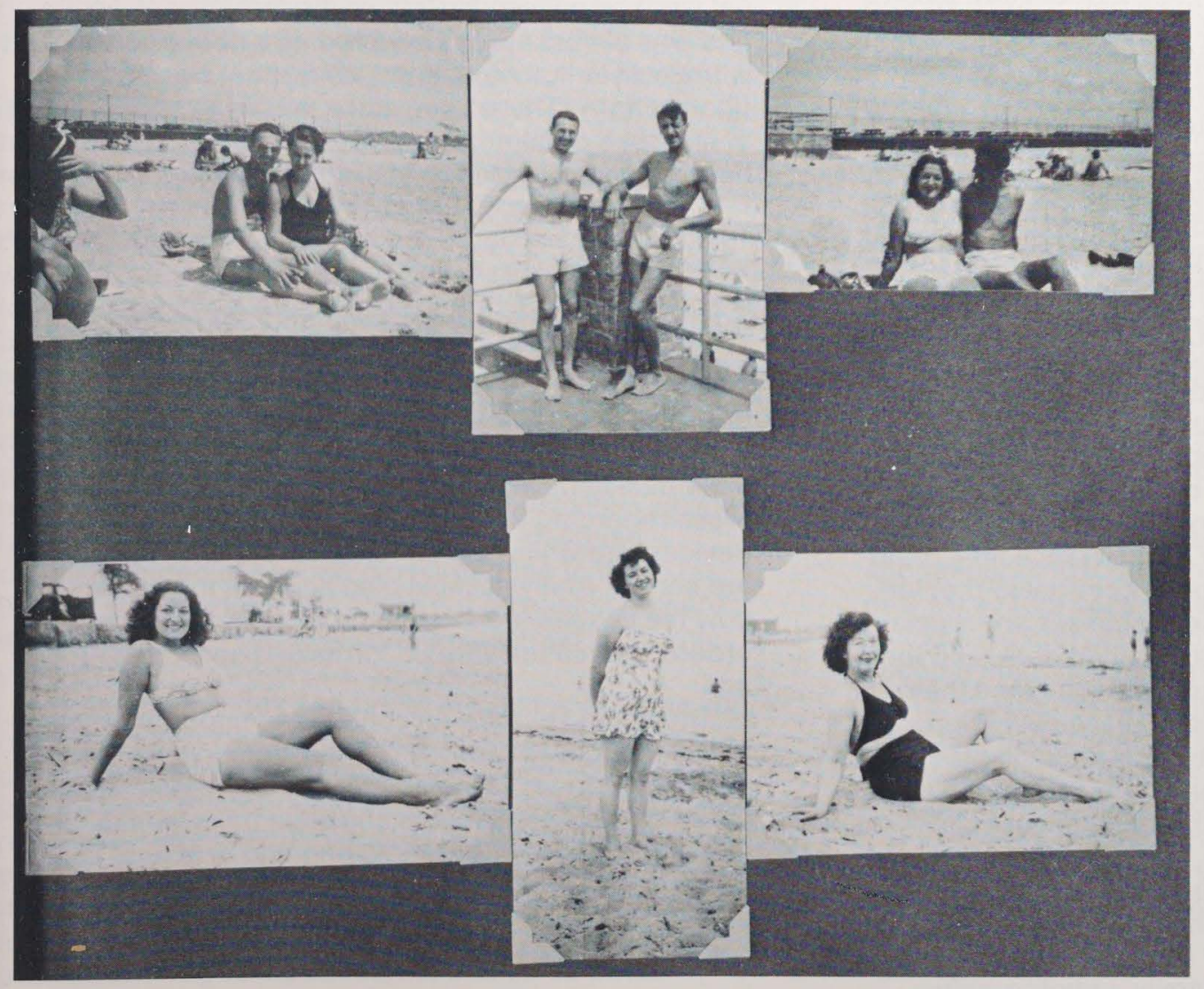

Figure 4 A day at the beach. (Courtesy of George and Helene Dargaty) 
Figure 5 (a, b, and c) An "oncamera" motif. (Courtesy of John and Arlene Westphal; Christopher Musello)

\section{Processing Events}

This category, added to Chalfen's framework (1974), incorporates any decisions, performances, and activities which determine and/or shape when film may be developed, printed, and mounted; what film will be processed; and how it will be processed. While these events may seem to hold little relevance for filmmaking, they must be regarded as a significant aspect of the symbolic manipulations inherent in the still photography medium. Initially, in this event all decisions regarding what is processed and how constitute a first phase of the editing events, and the decisions inherent to selection and manipulation of the printing process provide an order of control equivalent to that of the shooting event. For these reasons, then, processing events may be thought of as a distinct conceptual unit.

It is one of the distinguishing features of this photographic genre that the families using it place little or no emphasis on processing events. In contrast to the "art photographer," for whom these processes are crucial, many families' knowledge is very limited here, and the processes are often considered largely beyond their control. Few of the families studied have ever even sought to return prints to processers when dissatisfied with results, and much of the time they were unable to judge whether deficiencies were the result of their shooting or of the processing.

A number of home moders had, at one time or another, developed and printed their own photographs, but these activities were never integrated for any sustained period of time with the family's photography.

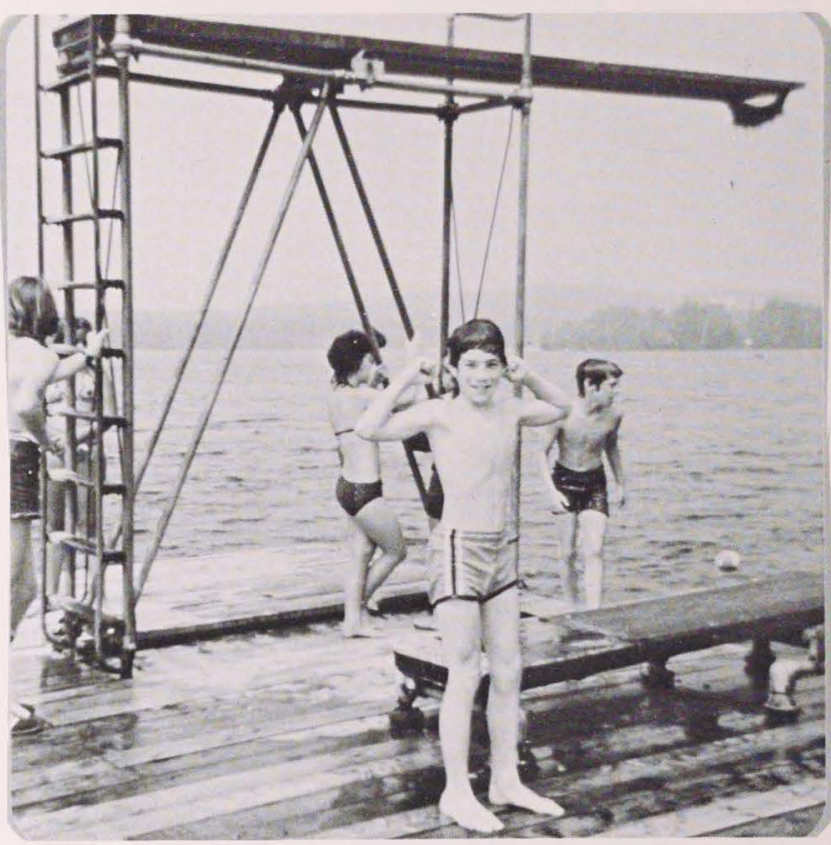

Most often this involvement occurred when the individual was young, usually before the arrival of children, and was almost always adopted as a hobby associated with "artistic" photography, as distinct from family photography. There were some limited exceptions, but in no cases did the family members continue in this hobby for more than five years.

\section{Editing Events}

Editing occurs after processing and before the products are seen or displayed. It may involve accumulating, eliminating, or rearranging a series or group of images into a specific order or sequence. This category is expanded from Chalfen's (1974) formulation to consider decisions about retaining pictures as well as those regarding the groupings, collections, or storage devices into which the pictures, slides, and negatives are sorted. Analysis must also account for where and how the images are stored and examine how they are ordered within the various forms of display and storage.

The editing event was considered important by the family photographers. They believed implicitly that the accumulation and assemblage of chronologically ordered photograph albums and slide trays was desirable and should be a steady, ongoing process. There was significant variation in attention and activity among families in the sample, but their efforts were 


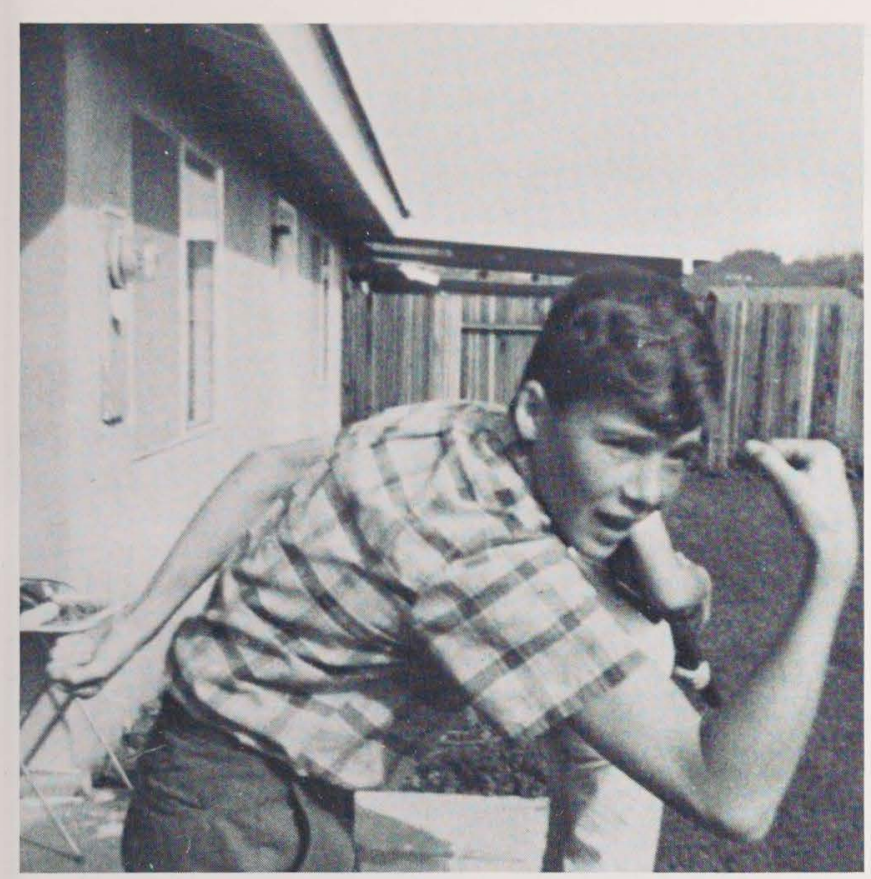

generally far below their expectations and were frequently a source of disappointment or even embarrassment.

Photographs potentially go through numerous editing phases in the home mode processes. When pictures and slides are first received, they are "left out" for viewing by family members, and at this time a rough cut may be made in which "blank" or unreadable images will be discarded. From this point slides will often be placed in carousels for storage, but photographs will most typically be shuffled off to drawers, boxes, or some general pool to be sorted in some unspecified future. A portion of the families studied organized their collections in an ongoing process, but a comparable number had never sorted their photographic products in any way. For the clear majority, however, sorting and organizing were activities which had fallen into neglect. As with shooting, young couples tended to pay the most attention to these activities, and although this could not be examined here, it appeared that editing was often taken up again later in life. ${ }^{6}$

When and if slides and prints are edited and assembled, decisions regarding inclusion or exclusion in the collection will turn primarily on the evaluation of subject matters. Photographs may be excluded if they are repetitive, strongly out of focus, or improperly exposed; only rarely will content be a criterion. Home moders value even the least decipherable of their images for the moments that they record, and as a result even poorly exposed, damaged, or blurred photographs will often be saved (Figure 6).

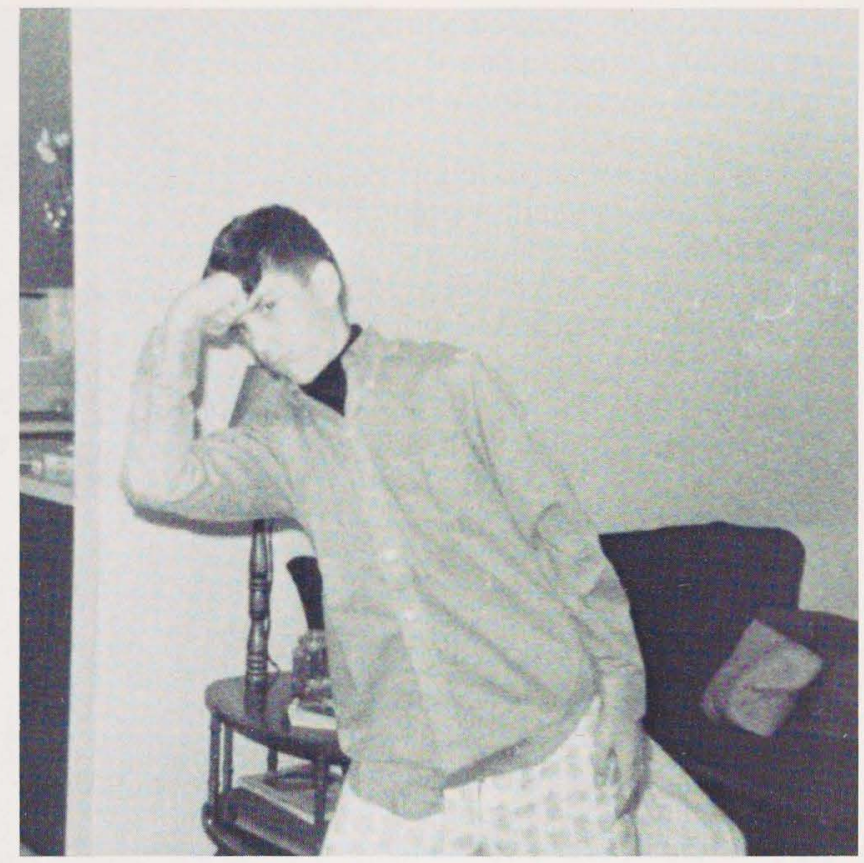

Although the actual storage units into which photographs were sorted were varied, the ongoing general family album seems to be the predominant organizing form, supplemented by a general pool of unsorted photographs. How each unit is organized may vary, but chronology is the dominant organizing principle. Smaller, discrete units might be edited for a specific time period or a particular subject (most often vacations) and then ordered chronologically within this theme. One highly favored organizational unit was a chronology covering the growth and development of individuals and families (Figure 7). Home moders also embellished their photography with written narratives and often extended their notions of photograph albums to include various types of memorabilia including such items as tickets, programs, report cards, and certificates.

As families age and become accustomed to viewing and responding to their own slide shows and albums, they take more care in deciding what photographs to include. As with planning events, then, these decisions become more complex as they are informed by a sense of what will have meaning and interest for family members in the future. This is one of the many manifestations of the future orientation which pervades and shapes the use of this mode.

Finally, the criteria for selecting photographs for wall displays were more discriminating, both semantically and formally, than for any other display unit. In 
Figure 7 A photo

chronology. (Courtesy of John and Arlene Westphal)

Figure 6 A family album favorite. (Courtesy of Donald Gribbons) $\nabla$

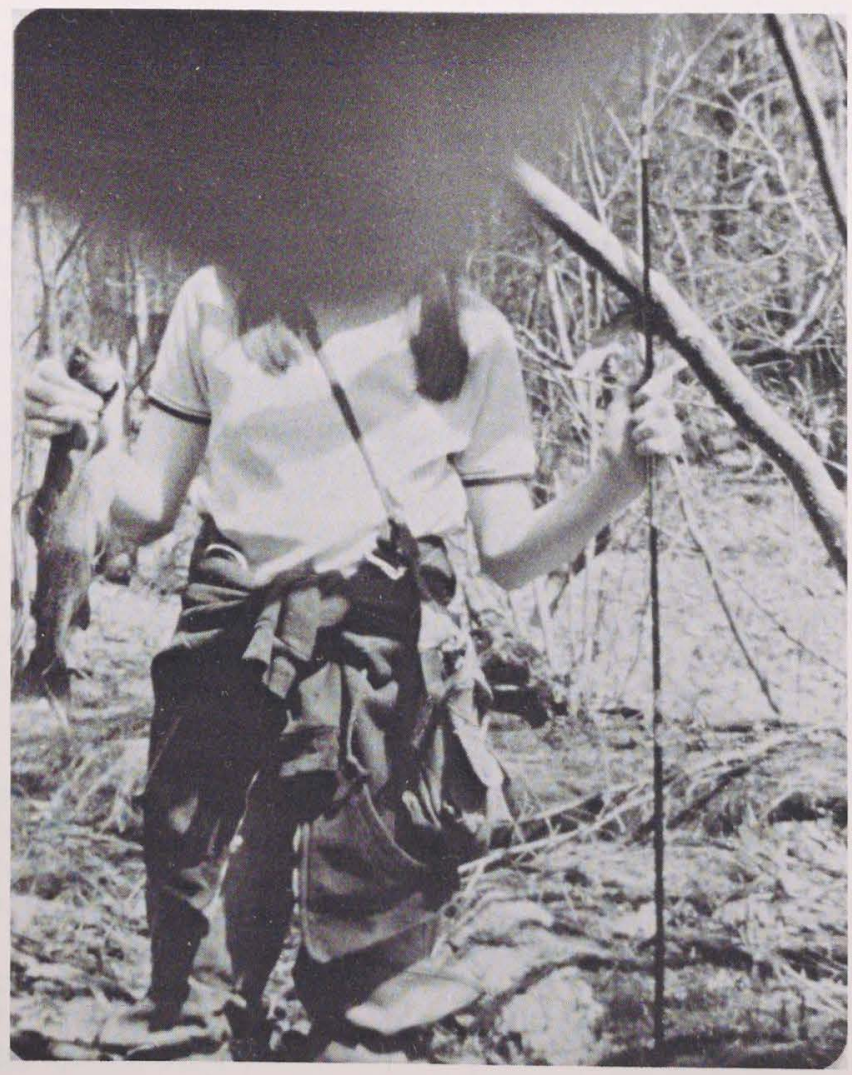

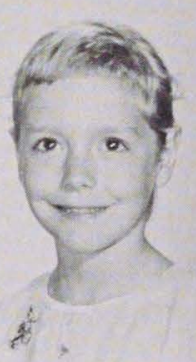

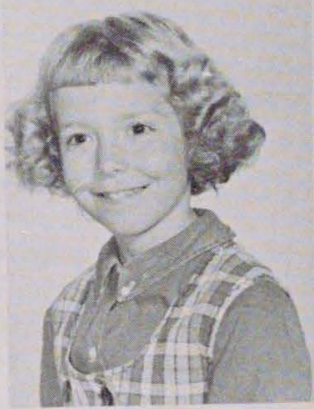

$1961+32$
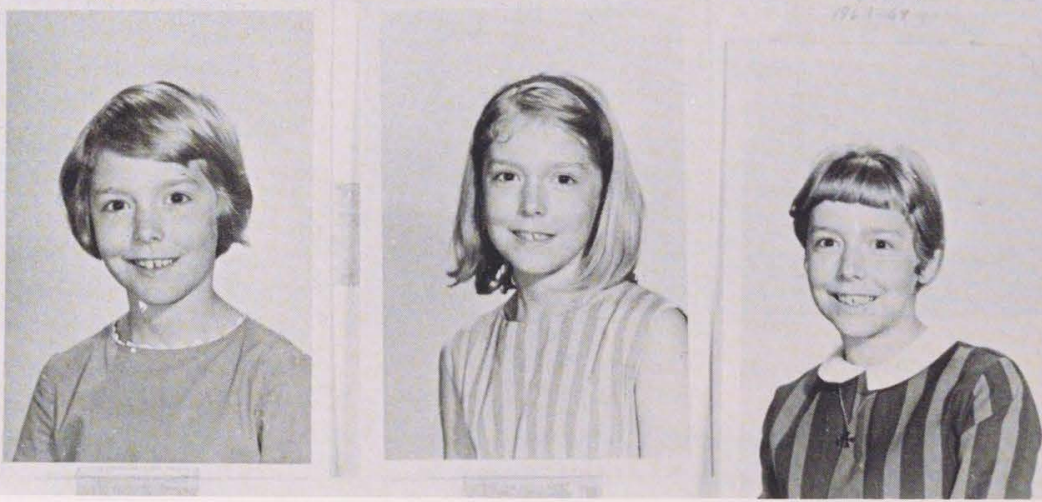

general, only photographs considered exceptional in content and at least competent formally are displayed. Most families made a strong distinction between public and private display, and though the distinctions vary, everyone felt they were "obvious" and could be assumed. Most consistently, families felt public displays should include formal portraits of family members, primarily the children or possibly the full family, frequently photographed for some special occasion. Private displays for areas such as bedrooms and family rooms were more inclusive and varied, and tended to include favorite photographs of exceptional personal and emotional significance. Once they were displayed in this way, "reediting," or replacement, was rare (except by the children), and wall photographs often spanned a period of up to ten years. 


\section{Exhibition Events}

These events include any activities or performances in which photographs are shown and viewed in a group or individual context. In order to explain the varied forms of display and storage of family photographs, it is useful to view them along a continuum going from exhibition to nonexhibition events, for some elements of family collections are stored and never seen, while others are on perpetual display. The exhibition category must therefore account for patterns of storage and the accessibility afforded different photographic groupings as an index of the type and extent of viewing they receive. The researcher is heavily dependent here on his informants' reports of what they do; thus an accounting of these conditions not only serves to describe a systematic behavior but also provides some independent insight into what viewing is possible. Beyond these considerations an analysis of exhibition events must aim at characterizing the nature of all viewing events.

The viewing events are perhaps the culmination, or even the very point, of the home mode process. A number of broad trends and patterns can be suggested about the ways in which families accomplish their viewing activities, and yet even with the small sample used here, the extent of involvement and the significance associated with these events as a family activity vary widely. The relation of these variations to family history, as such, seems clearly a matter for extended research. However, the way in which families treated and located their collections seems clearly correlated with their viewing practices. As I have already noted, family collections range from ongoing organization, with prominent displays of photographs and albums, to collections in which all pictures are deposited in boxes or barrels and stored out of easy reach. Some part of all families' collections is found in drawers and closets, but again the extent varies. In general, in this survey, it has been found that as collections move from greater to lesser accessibility, viewing is less and less a public matter; friends and relatives are less likely to be included in these activities, and when they are, viewing will be more selective. In addition, as the organization and accessibility of collections decline, the events of viewing and using family pictures seem to have less and less significance either as a family activity or as an important family resource.

Only a select portion of a family's collection was generally accessible and acceptable for public viewing. Most often photographs "left out" for viewing included "new pictures" or particular albums-usually the most recent general family album, vacation albums, or in the case of young families, baby albums. Those photo units reserved and stored for essentially personal and close family viewing included older fam- ily albums, weddings, "army albums," and collections which predated marriage. These personal images and collections were most often stored away in attics and basements.

The most accessible form of exhibition was, of course, the display of photographs on walls, tables, television sets, and bookcases. All families displayed pictures in this way, either publicly or privately, and it seems apparent that the public/private distinction itself may assume significance as a point of contrast between home moders. For some families felt that all display in public rooms was "inappropriate," while most families limited public room display to formal or posed images of family members. Those who shunned all display in parts of the home where visitors might readily view them generally placed no similar restriction on the exhibition of photographs in the "private" rooms, and at times did so quite extensively. In either case, we can note that these displays of the home mode often become fixtures or ornaments to family members and frequent visitors, so that they are only rarely noticed or discussed, and are even forgotten. Office photographs might receive similar attention; however, at times they are hung and consciously manipulated by home moders for their social value, much as wallet photos may be used and displayed in the course of social interactions. Nearly all the couples in this study were found to have photographs in their wallets or purses though many never showed or even viewed these themselves and seemed unsure of their reasons for carrying them. Yet these images were employed readily by those families who were most extensively involved with photography and by proud grandparents in interactions with others. Photographs were used in these contexts either to "update" people on family members, as a means of introduction, or simply as a basis for conversation.

As indicated earlier, the families which most actively and enthusiastically used this mode view photographs in a broad range of activities and with a broad circle of friends and extended family. However, the dominant movement within each family over the years was toward increasingly limited, personal, and immediate family use of these images. Family viewing occurs, at minimum, as an informal event stimulated by the arrival of new prints. Its most organized form typically occurs (and is perhaps required) in the viewing of slides. Families described viewing occasions as matters of "whim," frequently stimulated by one family member's (usually a child's) decision to search out a particular photograph or simply to browse through the collection. Interestingly, all couples stated that they rarely viewed pictures without the children being present; that is, parents uniformly conceived of this event as a family activity. 
The actual events of viewing were not examined systematically in this research. However, the significance placed on viewing photographs, the involvement of family members in sharing pictures, and the use of these events as important joint activities merit further study. This research suggests, for example, that as families view their photographs repeatedly a pattern of responses, observations, and interchanges develops around particular images. Such a patterning suggests, among other things, the construction of a set of shared interpretations, remembrances, and identifications around the photograph collection. In addition, it seems that the viewing event itself may be examined systematically and comparatively as a site for the evaluation of intrafamily interaction. For clearly, as families view their photographs, they respond not simply to the pictures presented but also with and for one another.

The sharing of photographs with friends and relatives was generally quite limited among home moders. Few families were found to maintain any kind of traditional group viewing events, and generally relatives were only shown photographs when they visited. Similarly, the viewing of family photographs with friends or visitors was almost never a planned event. Viewing with friends occurred most often to illustrate or reference a particular subject, especially when friends had shared photographed activity with the family or when the family had returned from vacation with "interesting" pictures. Most home moders, however, are reticent to show their photographs to friends, fearing to bore their guests or perhaps to appear egocentric, and many also considered it simply "inappropriate" because of the personal nature of the pictures. Public displays in the form of Christmas cards and birth announcements were nonetheless approved by all.

As with all the events examined so far, the exhibition events also incorporated conventionalized notions of appropriateness which contributed to the patterning of the process of the home mode. Home moders generally professed a sense of the great importance of family photography and set out to accomplish it in ways which were clearly structured by social notions of "how you do family photography." Once these pictures are produced, there is a significant variation in what families do with them and how they incorporate them into family life. ${ }^{7}$ Future research must study these events comparatively, across social and cultural groups, to clarify the nature of the patterns identified here and to discern the systematic social influences that produce variations in each of these activities.

\section{The Components of the Home Mode}

It should be recalled at this point that, as the framework set out here is employed in research, the communicative events and components are to be interrelated for the purposes of generating research questions and of ultimately characterizing and comparing genres of visual activity. The units are being discussed individually as much as possible in this presentation in the hope of providing some understanding of the regularities endemic to each aspect of the home mode process. The two final components in the framework (see Table 1), "message form" and "code," can be dealt with briefly. Simply put, the unit "message form" calls for designation of the form or means of expression. For visual forms the designation refers to the visual style under study, in this case home mode, or family, photography.

By incorporating a "code" component, Chalfen suggests with regard to film that an examination include "description of photographic habits, conventions, or routines (in shooting and editing) and a description of social habits and conventions," including patterns of on-camera behavior (Chalfen 1975a:97). It is through these patterned manipulations that Chalfen feels film styles or message forms will be defined. With respect to still photography, however, it seems clear that the units of any photographic code remain indeterminate (cf. Barthes 1975; Sekula 1975; Byers 1966) and, more pointedly, that family photography cannot be distinguished from other forms of photography on the basis of formal or syntactic features.

A code is understood here as "an organized subset of the total range of elements, operations, and ordering principles correlated with a field of reference that are possible in a given mode or family of symbol systems" (Gross 1974:59). Particular codes within any given mode are therefore generally to be distinguished by their distinctive organization of formal and syntactic elements. Two problems stand out in the application of this concept to family photography. Initially the analyst is confronted with that branch of commercial and/or "artistic" photography which either directly imitates or otherwise achieves or incorporates formal elements associated with the look and "feel" of family photography. Many of the images of Robert Frank's The Americans might be placed in this category, for example, as would the work of other artists who manifestly mug the snapshot "style" (cf. Greene 1975). On the other hand, there are photographers who shoot pictures of personal subjects for private use only and demonstrate a proficiency with their equipment which is not ordinarily associated with the family photographer. In fact, as indicated earlier, research has suggested that home moders can be ranked along a continuum of skills ranging from complete incompetence to professional capability. 
In the first case (that is, the snapshot aesthetic) the photographs may be distinguished from the images of the home mode primarily through an awareness of the history of their production and use, as well as of cues provided by presentation contexts, rather than through any evaluation of the formal elements of the photographs themselves. Similarly, it must be recognized that, while the images of the second case might be distinguished from home mode images because they exceed common notions of the formal components and standards of family photography, they are by definition artifacts of the mode precisely because of their usage. In both cases, it is not possible to distinguish the images of home mode from non-home-mode pictures solely on the basis of code elements. If a home mode genre is to be deciphered, it will be distinguished through the examination of the interaction of communicative behaviors, contexts, and artifacts and not through a specification of code elements. The code category here can thus yield no distinctive information in characterizing the home mode. Therefore, observations concerning formal/syntactic features have been incorporated elsewhere in this analysis as they become relevant.

\section{Participants}

From the beginning of this study, the home mode has been partially defined by characterizing its participants. It is a family medium used in the service of a family document, and a restricted pattern of family participation is consistently demonstrated; these factors focus and define the scope of the mode. The subjects are limited to a small network of immediate family members, friends, and relatives.

As to responsibility for shooting, it was found that in the majority of families in this study all members had used the family camera to some extent. Children frequently owned their own inexpensive cameras, but the larger share of family shooting was the obligation of the parents. Where photography was the domain or special skill of only one parent, women were as likely as men to be the primary photographer. Otherwise this task was divided informally between husband and wife according to areas of specialization or preference. Families also relied on professional photographers for baby pictures, wedding photography, portraits, and class pictures.

Those depicted in family albums may include a range of family, friends, and relatives. As a family ages, however, the range generally narrows because relatives are included with less frequency and the immediate family, most especially the children, becomes the primary focus. Significantly, it was found that following the birth of children the on-camera participation, or visibility of husband and wife in the family's collections, frequently dropped dramatically, often to near exclusion. When questioned, most parents claimed that the idea of pointedly photographing each other seemed irrelevant or unnecessary. They therefore appear only infrequently through the bulk of their collections, possibly resurfacing as individuals and as a couple (as in prechildren albums) when the children leave home and especially when they travel.

The determination of who is to be on each side of the camera works demonstrably to shape the nature of the entire picturetaking process and its subsequent products in this mode. In a picturetaking situation which may be particularly laden with conventional prescriptions for behavior, as in studio photography or instances in which a group poses in a traditional manner, the influences of the interaction among participants will be diminished, but not eliminated. However, when an event becomes less rigidly defined in candid, spontaneous, and surprise shooting, photographs and photographic behaviors become increasingly responsive to the nature of the interactions among participants both on and off camera. Yet these photographic behaviors still frequently take a highly regularized form, as in the common ritual of children "sneaking" pictures of appropriately indignant parents, in the requirements imposed on a husband/photographer by a wife/subject, and the tendency of a child to "mug" for one parent more than the other. Such interactions may become as stable and practiced as those institutionalized within a family or any fixed group of people.

In the editing events, different forms of display (office photos or wedding albums, for example) obviously will be viewed by different audiences. Pictures on display in public rooms may be seen by any visitor, but generally only relatives and the closest family friends will view the albums or extended sections of the family collection. The viewing event is again primarily an activity of the immediate family.

The pattern of participants described in the home mode collection is that of a select group of individuals which tends to narrow as families age. This limitation yields a closed network of social relationships which impose a variety of restrictions and influences on the performances and behavior of each of the photographic events. 

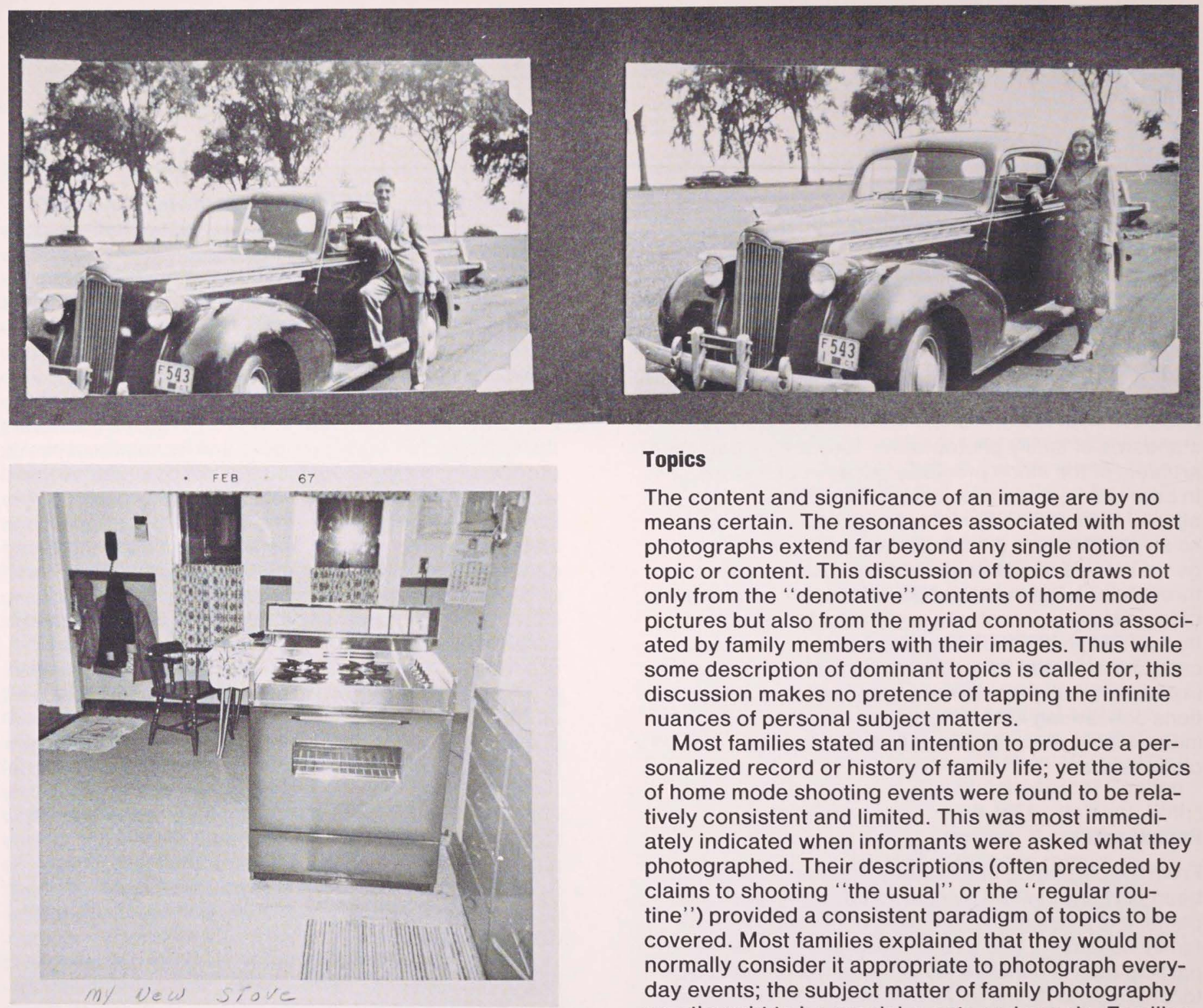

Figure 8 [a, b, and c) Local topics: new possessions. (Courtesy of George and Helene Dargaty; John and Arlene Westphal)

\section{Topics}

The content and significance of an image are by no means certain. The resonances associated with most photographs extend far beyond any single notion of topic or content. This discussion of topics draws not only from the "denotative" contents of home mode pictures but also from the myriad connotations associated by family members with their images. Thus while some description of dominant topics is called for, this discussion makes no pretence of tapping the infinite nuances of personal subject matters.

Most families stated an intention to produce a personalized record or history of family life; yet the topics of home mode shooting events were found to be relatively consistent and limited. This was most immediately indicated when informants were asked what they photographed. Their descriptions (often preceded by claims to shooting "the usual" or the "regular routine") provided a consistent paradigm of topics to be covered. Most families explained that they would not normally consider it appropriate to photograph everyday events; the subject matter of family photography was thought to be special events and people. Families readily and regularly listed the events of the home mode repertoire as children, vacation/trips, family gatherings, family activities, Christmas, birthdays, graduations, and weddings. The scope of shooting, of course, varied-some families covered only Christmas and a few other family events, while others shot steadily throughout the year. Yet even among the most voracious photographers, most shooting was consistent with a common model of family topics.

An informal survey of the family collections shows holidays, vacations, and special events to be a major and consistent spur to shooting throughout family life. Christmas (as a secular event) seemed the most common occasion for shooting, while Thanksgiving and Easter or other religious holidays (depending upon the group) were also regular topics. Certain key aspects of these events were photographed routinely each year, such as the giving of gifts, new clothes, and the gathering of the family. These aspects, as with other special events, were a dominant focus of family shooting because of (1) their "extraordinary" nature; (2) the significance families associated with them (and, conversely, the role of picturetaking in communicating or 
conferring significance upon the events); and (3) because of their presumed appropriateness as subjects for photograping and recollection. Other such "important" events included births, birthdays, graduations, weddings, and family visits. This category of special events may become meaningful, however, only if it is explored comparatively in future research so that conceptions of what constitutes "special" and "important" can be linked to particular social and cultural groups.

Vacations and trips were a particular order of special event. Travel photos inspired the most self-conscious attempts at "documentation" of any home mode shooting, emphasizing places, buildings, local practices, and the unusual. By contrast, photographs of vacations in fixed and/or familiar locales seemed to stress people engaged in activities and, as with most family shooting, sharply minimized the photographing of places and objects. Local activity around the home was photographed, though, only as the unusual intruded, and this was most often the first area where photography fell into neglect. Included here would be new or valued possessions, pets, a family football game, "catching the big fish," or occasional evidentiary shots of fire damage and successful gardens (Figures 8a, b, and c).

People are overwhelmingly the subject matter of the home mode. Any of the topics just discussed may find their most common realization in the simple depiction of a person or group, quite often without any detailed or recognizable visual context. As people become the specific topic, however, the pictures are increasingly directed toward, and evaluated in terms of, their qualities and effectiveness as likenesses. In studio or portrait photography, for example, the event, the photographer's intent, and the subsequent use of the photograph are defined by the effort to portray the person. With the addition of candid, spontaneous, or surprise techniques, the efforts at portrayal are typically extended toward "catching" or documenting the individual in activities ranging from the special to the banal; yet these photographs do not, to their users' sensibilities, incorporate the everyday as a topic of the mode.

The use of candid techniques for portraiture also serves to extend certain general notions of appropriate subject matter. The subject matter of the various home mode topics is generally patterned and guided by conventions of propriety regarding presentation (participants should look "good") and of activities or occasions for shooting (subjects should not be depicted in activities considered obscene, embarrassing, or in some other way socially objectionable). Generally, topics are limited to public or family activities and to the best presentation of the person. However, with the candid and, particularly, the surprise photograph, people may be photographed seemingly at any time.
Emphasis is frequently placed directly on violating normal shooting conventions to photograph people when they least want to be shot, when they are looking bad, or when they are engaged in an activity directly embarrassing to them or embarrassing as a photographic subject. Thus we frequently see in such shots seminude persons, mothers in curlers, and people vomiting, urinating, or passed out (Figure 9). In this way, topic conventions have essentially provided for an alternative topic and treatment form inasmuch as home moders may employ these "improper" alternatives to produce "extraordinary" or "outrageous" portraits intended to tease, embarrass, anger, or amuse one another.

Family photographers may, therefore, prove relatively versatile in the use of the camera as they photograph their accustomed selection of people. However, it was found that most families brought a basic shared conception of prescribed topics to their photography and that the bulk of their shooting remained within this structure. The pattern is clarified a bit more when the topics shunned by the family photographer are realized. The negative aspects of family life such as pain, death, anger, and sorrow are not seen; work, school, church services, and daily events such as cleaning, eating, watching television, or rising and dressing in the morning are not shown. The "family document' seems to present a highly selective and exclusive sampling from the events and activities of the family's life.

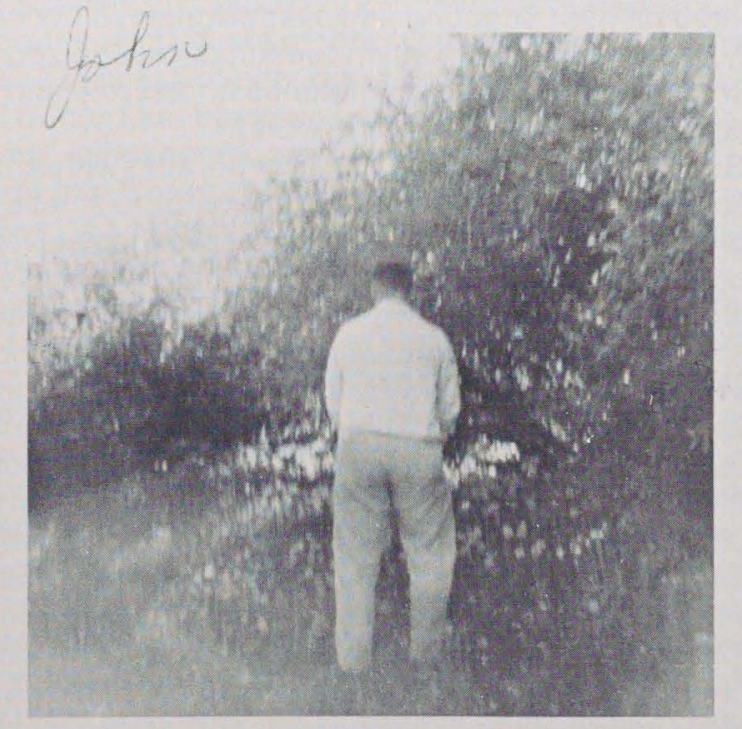

Figure 9 A surprise photo. 


\section{Settings}

This component incorporates both the settings photographed and the locations in which home mode activities occur. A review of home mode photography reveals a patterned approach to and conceptualization of "place" among family photographers. As mentioned earlier, many events, occasions, and places find their portrayal in the depiction of people, frequently without other visual contextual data. Christmas or Thanksgiving may be represented through shared icons (Christmas trees, for example); however, the majority of settings and events are realized in "contextfree" pictures of smiling people in lawn chairs, adults hugging children, and so on. Home mode photographers in fact rarely actively considered or sought to depict elements of the setting but rather shot where subjects "were" or sought to control the setting as a backdrop. Here they might attempt to avoid background distractions or meet such technical needs as lighting or locating children strategically. But the "sense" and substance of setting was nonetheless restricted to that which was located within the frame and surrounding the subject.

It was primarily only as settings became less familiar, most often in travel and vacation photography, that they received attention as objects for conscious representation. At these times visual aspects of the settings-panoramas, architecture, monuments, and so on-were identified and isolated for depiction or inclusion as people were posed and associated with them. It is only at this point that home moders commented on their shooting as an unfortunate, if necessary, selection from an environment, or recognized their photographs as discontinuous or discrete and disembodied fragments of the world.

Settings were occasionally incorporated with symbolic intent as a matter of identification or aesthetic appreciation by families who considered themselves "outdoors people." However, it is generally only as setting elements transcend the typical and everyday or hold out the interest of the unfamiliar that family photographers even begin to attend to them. Most shooting occurs in familiar locations, often in and around the house itself (often the kitchen or living room, but not bathrooms, and rarely in bedrooms), with minimum attention to the location. However, a significant pattern in this local shooting was found in the informal establishment of "ritual locations" in which subjects would be placed for pictures. These settings were generally defined more by traditional usage than by conscious choice, and they most commonly incorporated what family members considered the "nicest" features of the home (a fireplace, staircase, or piano, for example) as a positive reflection of both the family and the particular subjects.
Consistent with the selection of home mode topics, everyday life is rarely photographed, and settings per se are most often incorporated only as they host the "special" or themselves become unusual or unfamiliar. Shooting away from home does not extend freely to the rest of the world-we do not see laundries, subways, or supermarkets. The selection of home mode settings is patterned and restricted broadly by conventions regarding appropriate settings as well as by fundamental orientations to the relevance and significance of surroundings to the purposes of family photography.

\section{Documentation and Communication in the Home Mode}

The analysis and description of family photography in this paper suggests that what the home moder does with his camera and photographs is delimited and sharply focused by a system of conventions and rules. What seems to emerge is a structure of conventional usage which circumscribes and to some extent specifies the events and components of the process while allowing for significant variation in each family's participation. This research has further indicated that home moders do not employ the photographic code in any uniform or shared system of signification. The implications of these findings for both our assumptions about the nature of family photographs as "documents" and the function of family photography in processes of communication are fundamental. The examination of these assumptions and their grounding in empirical data are primary to the formulation of any research utilizing these materials.

The communicational properties of these documents might most readily be characterized in terms of the articulatory and interpretational processes through which they are produced and used. As characterized here, the processes of articulation are shaped by patterns and routines both in the selection of subject matters and in the use of the camera. Notions of the "appropriate" or "desirable" appear to guide the choice of topics and participants for shooting, and therefore generally circumscribe and regularize the contents of the family collection. Family photographers, for example, expressed the goal of recording the "growth and development of the family," and yet in common practice they sought almost exclusively to record their children. Parents appear only infrequently in these collections, so that the collections become scant documentations of adult life and only incomplete representations of family life. 


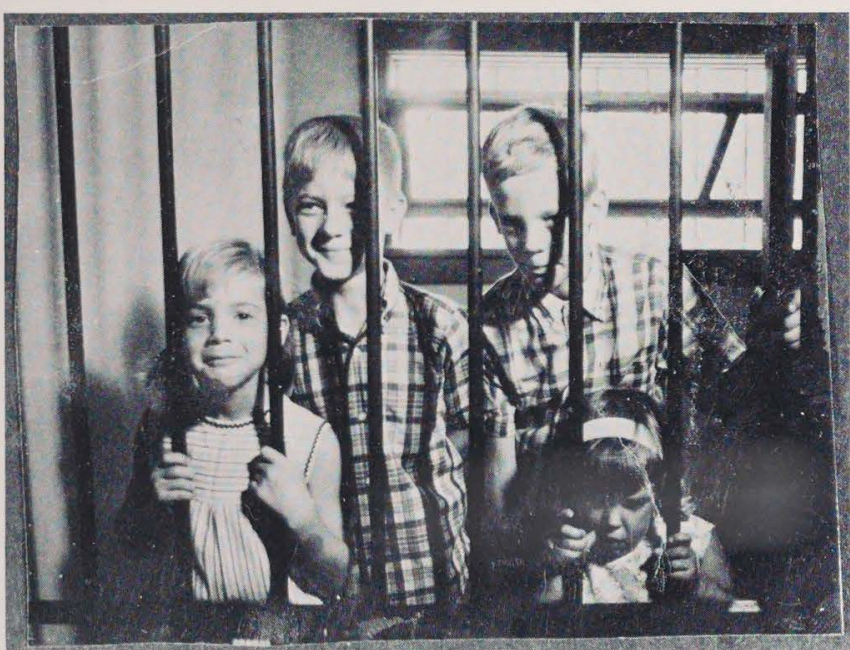

Figure 10 "This was the World's Fair in Montreal." (Courtesy of Richard and Martha Perkins)

Routines and patterns in picturetaking work similarly to structure these materials. Among those already mentioned are the frequent practice of documenting recurring events, like Christmas, through a regular set of shots; the conventional use of a limited and restrictive range of camera styles; the tendency to record events without incorporating contextural information (Figure 10); and, finally, long-term trends in family shooting which establish a pattern of broadest documentation in the family's younger years followed by an increasingly narrowed account of events over time.

Seemingly all phases of home mode use are fundamentally based in what Sekula (1975:37) has termed a "realist folk myth," through which photographs are conceived by home moders as mechanical recordings of real events. The processes of articulation accordingly received limited conscious attention from family photographers in this sample, and syntactic control was generally restricted to a small repertoire of considerations. Many home moders displayed an extensive formal competence with formal elements in discussing criteria for evaluating photographs; representational value, however, rather than aesthetic or expressive properties was the primary focus of evaluation. And even among the most sophisticated photographers in this study, the considerations which finally guided picturetaking were limited primarily to centering subjects, getting enough light, controlling background distractions, and "shooting a lot.'

Symbolic manipulation in the home mode thus focuses largely on the selection and presentation of oncamera elements rather than on their mediation, and symbolic implication is manifested predominantly through these on-camera events. The symbolic articulation becomes a kind of minimal nonevent to the family photographer: his goal is reportage, as distinct (in his conception) from expression, and he achieves his purposes through the simple mechanical re-presentation that he believes the camera and photograph offer.

As these images are viewed and interpreted, home moders generally assume little or no intent beyond the iconic referential components, and accountability for syntactic manipulations is also minimized. Meanings and interpretations are most often based on a belief in the photograph's value as a document of natural events and on recognition of its iconic referents. The photographic allusion is increasingly expanded, however, as viewers interact with the natural events depicted and draw references and significances from a broad range of events, experiences, people, and responses which they recall, derive from, relate, and attribute to the depicted contents.

This affective investment or extension of the symbolic reference by the viewer was discussed by Sekula (1975:42) in another context. He explains the interpretive strategy:

More than an illustration [the photograph becomes] an embodiment; that is, the photo is imagined to contain the autobiography. The photograph is invested with a complex metonymic power, a power that transcends the perceptual and passes into the realm of affect. The photograph is believed to encode the totality of an experience, to stand as phenomenological equivalent.

In similar fashion, the family viewer employs the photograph both as a literal reference to the events depicted and as a stimulant to thoughts, associations, and memories related to the event. In this sense, as family members view and interpret their photographs, the iconic reference encodes the "totality" of the experience and assumes a metaphoric significance.

The meanings and significances associated with the home mode photograph are therefore not encoded or derived through any articulatable code. Rather, expression and signification are brought to and invested in the family photograph through the processes of interpretation. The use of this symbolic form thus constitutes a process of personal signification and attribution rather than communication and remains, to a large extent, idiosyncratic and inaccessible to others (cf. Worth and Gross 1979).

The use of the home mode seems heavily reliant on verbal accompaniment for the transmission of personal significances. Photographs presented to others are typically embedded in a verbal context delineating what should be attended to and what significances are located in the image, and providing contextual data necessary for understanding them. A certain degree of structural recognition may be provided for and recognized in the construction of albums or photographic series. These orderings may indicate temporal or spatial relations between the elements depicted, or even some general form of association. However, the placement of a photograph in the context of a family collection does not prescribe strategies for its interpretation as would the placement of a picture in a newspaper, 


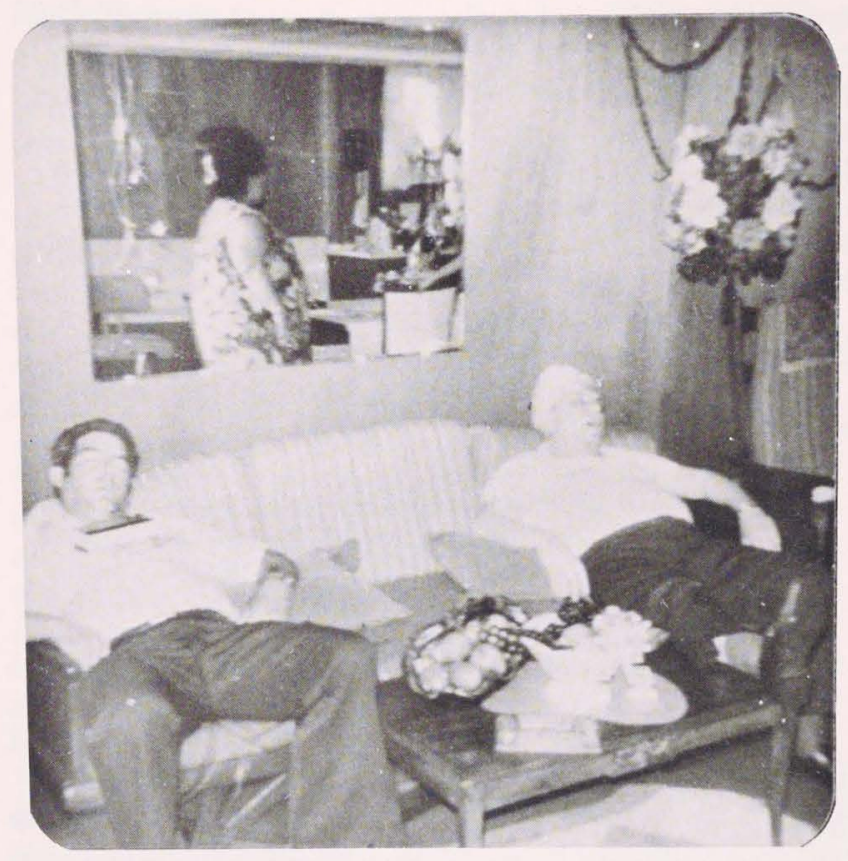

Figure 11 Woman in mirror. (Courtesy of Sam and Anna Fannelli)
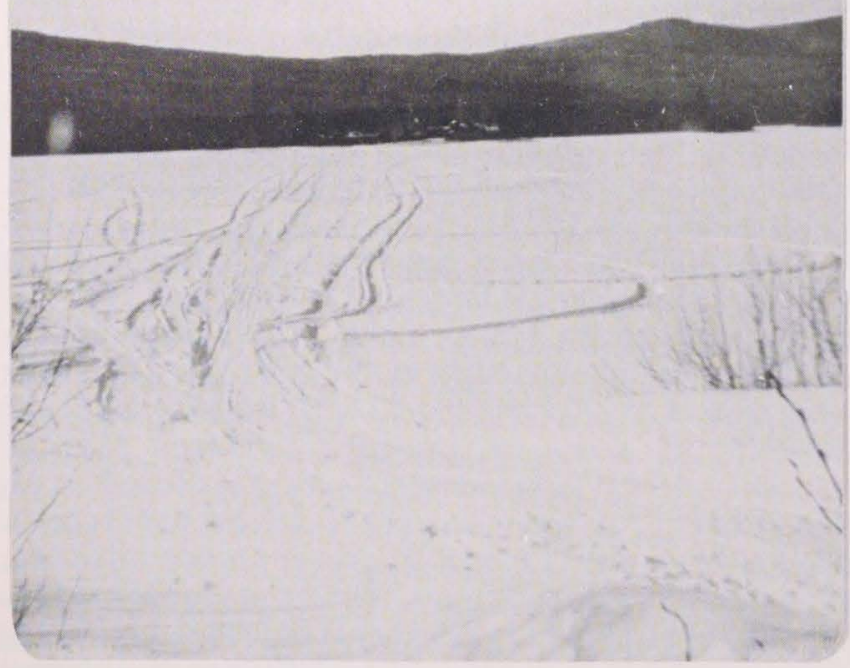

Figure 12 Snowmobile tracks. (Courtesy of John and Arlene Westphal) for example, where the photo is by convention treated as the simple documentation and representation of "objective realities." As a meta-communicative context, the placement of the photograph in a family collection implies the investiture of personal significances and prescribes attributional strategies for interpretation; it does not provide the viewer with an explicit system of conventions and rules for decoding the home mode message form.

Family photography and the family photograph collections pose a number of problems for those who would understand them as documents of family life. Through knowledge of the social behaviors guiding their production and use, it would seem that they constitute conventionalized records of selected aspects of family life. But when viewers attempt to account for the ways in which home moders produce and interpret these images, it is frequently found that even the iconic references relevant to users cannot be deciphered from these photos (Figure 11, for example, is valued as a rare image of the woman reflected in the mirror, and Figure 12 is a record of snowmobile tracks, not a landscape). Similarly, viewers often cannot determine from a family photograph the range of contextual data necessary to interpret the events depicted, and they clearly cannot anticipate the range of significances attributed to the images by their users. As such, the researcher/viewer's ability to interpret either denotative or connotative significance from the images of the home mode in and of themselves is sharply restricted. Further, the home mode photograph is not a document of fixed value in family life. Because interpretations are based in processes of recall, over time the power and value of these images may evolve and change or even be lost as memory decays (Figure 13). ${ }^{8}$ Thus photograph collections as documentary resources are perhaps more closely associated with an oral rather than a written tradition (cf. Goody and Watt 1962).

That the images of the home mode function in the storage and transmission of historical accounts and personal beliefs and experieıce seems implicit from their use in daily life. However, what can be known from the photographs themselves seems clearly restricted, as any decoding scheme must account for the nature of the encoding process and the nature of subsequent usage. All too often, however, researcherseven those purportedly dealing only with iconic elements-overlook such matters as use, context, and social convention as well as the technical artifacts of the photographic process to make unwarranted inferences from these materials (Akeret 1973; Hill 1978; see also Chalfen 1975b for comment on Akeret). This research has suggested that, to the extent that researchers seek to understand the uses and meanings associated with these images (and the mode itself) by their users, they must locate them in the social con- 


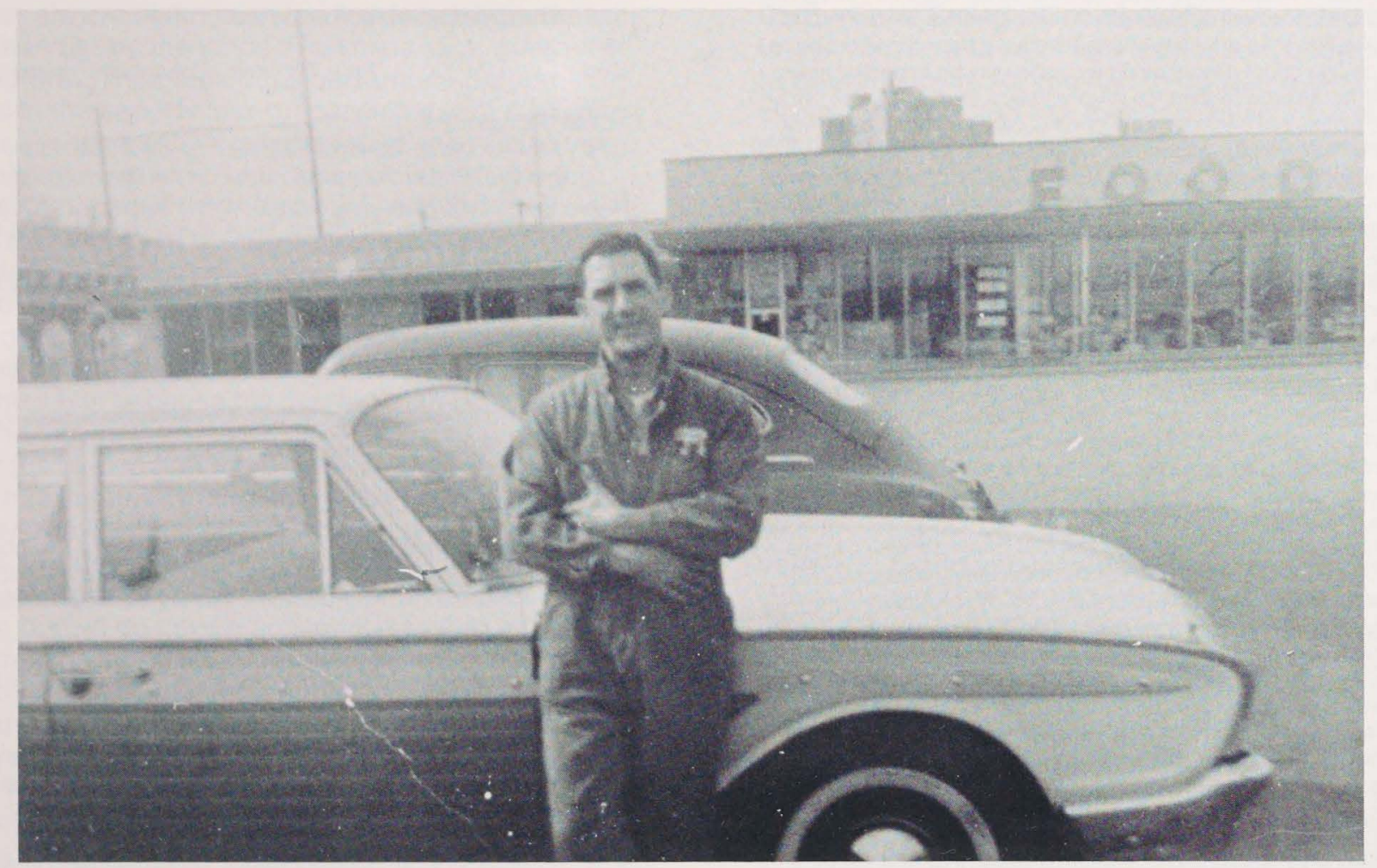

Figure 13 Differing interpretations:

Mrs.: "Oh, look at baldy! Here's a picture I posed of Sam with a haircut."

Mr.: "This is a picture of our new car."

(Courtesy of Sam and Anna Fannelli)

texts of their production and use. Home mode photography is a communicative activity, and its products, rather than being viewed simply as discrete articulations, might best be understood as communicative resources situated within and integrated with ongoing processes of social interaction.

\section{Notes}

1 Home mode photography can be defined as the body of still photographs and photographic transparencies produced and accumulated by and for family members within the context of family life. These images are made for private, as opposed to public or artistic, use and are to be distinguished from the latter primarily by the private context in which they are used rather than by any technical or formal quality of the images themselves.

2 This essay draws on the author's masters thesis, "Home Mode Photography: A Study of Visual Communication and Interaction in Everyday Life" (1977). See also Musello (1979) for a discussion of home mode functions.

3 There are numerous examples of this type of event, but they were found only in families for whom photography was an ongoing and established process fairly well integrated into the events and customs of family life. These include pictures of the first day of school and photographs of the entire family gathered on the same porch each year. One intriguing example encountered several times was the "last picture." This was seen with groups of older people and groups who were close to an elderly person. They involved posing together at some regular interval in conscious anticipation that one of their number might die soon. The image would thereby serve as the last picture of that person and the original group 
4 Sandra Titus (1976) has suggested an interesting basis for these inequities in family shooting. She suggests that photographs are valuable to couples as they reflect and promote transition to parenthood through the display and reinforcement of appropriate role behaviors. Photographs taken with the first child are as such produced in a transitional period as the young couple adopt new roles. The couple may be expected to be increasingly acclimated to parental roles with successive children; as a result more pictures of the initial transition will be taken, and these will tend to show more images of parents holding and feeding the child as well as more individual photos of the child. I would add that such an interpretation can be readily extended to the photographic behaviors of new grandparents.

5 Rudisill (1971) has not only suggested that such a catalog of standard postures exists but states that they date from the introduction of photog raphy to the public via the daguerreotype. At that point, he feels, Americans came to adopt a set of standard postures and approaches to the lens. What emerged was a "national iconography" — a set of standard poses conformed to even as the subjects attested to the medium's "absolute reality" and "naturalness. " That such a set of conventional poses exists now seems supported by the sample observed in this study. Such speculation should be subjected to a systematic and broad-based survey, however, before any attempt is made to suggest what these poses might be or how they might be classified.

6 The determination of when individuals edit and assemble their albums has significant ramifications for the nature of the family photograph album as a source of information about family life. Where albums are "built" years after the photos were taken, people are probably reconstructing their past, and since memories associated with the images often fade as time passes, we may speculate that those which cannot be identified would not be included in the collections. Also, as will be discussed, a tendency tô remove repetitive, bad, unfocused, or frivolous shots was identified in many families that have reedited or intend to reedit their collections. Thus albums put together in later years would be documents which are to some extent, sparser and of a different nature from those assembled continuously. Each type might well reflect a different set of criteria for inclusion and differing notions of what is significant and appropriate for storage and future use.

7 For a consideration of this variation and a presentation of case histories, see Musello (1977, chap. 5)

8 While the occasions of some photos are recalled over long periods of time with startling clarity, it was often found that a large part of any family's viewing was spent identifying specific individuals, places, occasions, and events depicted in older photographs, and many were simply forgotten by their owners. Some informants suggested that these pictures were then "pointless" or "meaningless" to the makers. However, in general, the past meanings were transformed by present interpretations. In some instances it was found that, as specific identities and contextual information were lost-as in the case of a college prom, for example - attentions and attributions directed to the photograph were generalized and a more stereotypic significance was derived. The prom photos served less as pictures of specific friends, dates, and minute occurrences than as broader reminders of events and good times in college days

Alternately, the approach to the images may become less metaphoric and more specifically referential. Viewers frequently directed their attention to the presence and nature of the artifacts of another time. Many took note of old clothes and cars in unidentified scenes or marveled at how homes were decorated or furnished in these "contextless" photographs. As such, many older pictures took on a new or differently weighted significance and were highly valued as representations of times past.

\section{References}

- Akeret, Robert

1973 Photoanalysis. New York: Wyden.

- Byers, Paul

1966 Cameras Don't Take Pictures. Columbia University Forum $9: 27-31$

- Chalfen, Richard

1974 Film as Visual Communication: A Sociovidistic Study in Filmmaking. Ph.D. dissertation, University of Pennsylvania.

1975a Cinema Naïvete: A Study of Home Movie Making as Visual Communication. Studies in the Anthropology of Visual Communication 2:87-103.

$1975 \mathrm{~b}$ Review of Photoanalysis. Studies in the Anthropology of Visual Communication 1:57-60

1976 Studies in the Home Mode of Visual Communication. Working Papers in Communication and Culture 1:39-62.

- Goody, J., and I. Watt

1962 The Consequences of Literacy. Comparative Studies in Society and History 5:304-326.

- Greene, Jonathan, ed.

1975 The Snapshot. Aperture 19:1

- Gross, Larry

1974 Modes of Communication and the Acquisition of Symbolic Competence. In Media and Symbols: The Forms of Expression, Communication and Education. David Olson, ed. Chicago: University of Chicago Press

- Hill, May Davis

1978 Hidden Stories in Your Photographs, pts. I, II, III. Family Heritage $1(1,2$, and 3$)$.

- Hymes, Dell

1964 Introduction: Toward Ethnographies of Communication. In The Ethnography of Communication. Dell Hymes and J. Gumperz, eds. (A special issue of the American Anthropologist, vol. 66, pt. 2. The Hymes Introduction appears on pp. 1-34.)

1974 Foundations in Sociolinguistics. Philadelphia: University of Pennsylvania Press

- Musello, Christopher

1977 Home Mode Photography: A Study of Visual Communication and Interaction in Everyday Life. Masters thesis, University of Pennsylvania.

1979 Photography in Everyday Life. In Images of Information: Photography and Social Science Research. Jon Wagner, ed. Beverley Hills, CA: Sage.

- Rudisill, Richard

1971 Mirror Image: The Influence of the Daguerrotype on American Society. Albuquerque: University of New Mexico Press

- Sekula Allan

1975 On the Invention of Photographic Meaning. Artforum: 36.

- Titus, Sandra

1976 Family Photographs and Transition to Parenthood. Journal of Marriage and the Family 38(3):525-530.

- Wolfman, Augustus

1974 The 1973-1974 Wolfman Report on the Photographic Industry in the United States. New York: Modern Photography Magazine.

- Worth, Sol

1972 Toward the Development of a Semiotic of Ethnofilm. PIEF Newsletter $3: 2$

1974 Pictures Can't Say Ain't. Proceedings of the International Conference on Semiotics, Milan, Italy.

1976 Doing Anthropology of Visual Communication. Working Papers in Culture and Communication 1:2-22.

-

1972 Through Navajo Eyes: An Exploration of Film Communication and Anthropology. Bloomington: Indiana University Press.

- and Larry Gross

1972 Symbolic Strategies. Journal of Communication 24:27-39. 